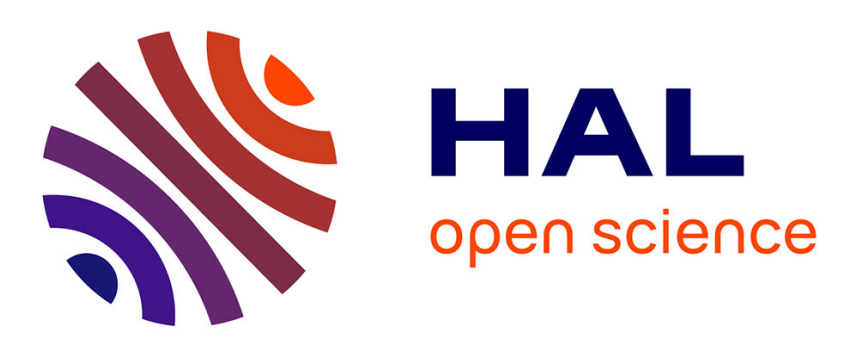

\title{
Collective radical oligomerisation induced by an STM tip on a silicon surface
}

Elie Geagea, Judicaël Jeannoutot, Michel Feron, Frank Palmino, Frédéric Cherioux, Christophe Thomas, Alain Rochefort

\section{- To cite this version:}

Elie Geagea, Judicaël Jeannoutot, Michel Feron, Frank Palmino, Frédéric Cherioux, et al.. Collective radical oligomerisation induced by an STM tip on a silicon surface. Nanoscale, 2021, 13 (1), pp.349 354. 10.1039/D0NR08291K . hal-03186582

\section{HAL Id: hal-03186582 \\ https://hal.science/hal-03186582}

Submitted on 31 Mar 2021

HAL is a multi-disciplinary open access archive for the deposit and dissemination of scientific research documents, whether they are published or not. The documents may come from teaching and research institutions in France or abroad, or from public or private research centers.
L'archive ouverte pluridisciplinaire HAL, est destinée au dépôt et à la diffusion de documents scientifiques de niveau recherche, publiés ou non, émanant des établissements d'enseignement et de recherche français ou étrangers, des laboratoires publics ou privés. 


\title{
Collective Radical Oligomerisation Induced by STM tip on a Silicon Surface
}

\author{
Elie GEAGEA, ${ }^{\text {a }}$ Judicaël JEANNOUTOT, a Michel FÉRON, ${ }^{a}$ Frank PALMINO, ${ }^{a}$ Christophe M. THOMAS, ${ }^{\mathrm{b}}$ Alain \\ ROCHEFORT, ${ }^{\mathrm{c}}$ and Frédéric CHÉRIOUX*a
}

Over the past decade, on-surface fabrication of organic nanostructures has been widely investigated for the development of molecular electronic components, catalysts, and new materials. Here, we introduce a new strategy to obtain alkyl oligomers in a controlled manner using on-surface radical oligomerisations that are triggered by electrons between the tip of a scanning tunnelling microscope and the $\mathrm{Si}(111) \mathrm{V} 3 \times \mathrm{V} 3 \mathrm{R} 30^{\circ}-\mathrm{B}$ surface. This electron transfer event only occurs when the bias voltage is below $-4.5 \mathrm{~V}$ and allows access to reactive radical species under exceptionally mild conditions. This transfer can effectively 'switch on' a sequence leading to the formation of oligomers of defined size distribution thanks to the on-surface confinement of the reactive species. Our approach enables new ways to initiate and control radical oligomerisations with tunnelling electrons, leading to molecularly precise nanofabrication.

\section{Introduction}

On-surface synthesis under ultrahigh-vacuum (UHV) conditions has attracted considerable attention as a means to generate new and stable molecular structures, as it offers an alternative and highly efficient strategy for controlling chemical reactions and allows direct observation or induction of reaction pathways by scanning tunnelling microscopy (STM).[1,2] However, so far, the number of $\mathrm{C}-\mathrm{C}$ bond-forming chemical reactions reported on surfaces remains very limited and have mainly developed on coinage metal surface [2] or insulators [3] but never on a silicon-semiconductor. The development of on-surface chemistry on a silicon surface is still a major scientific and economic challenge because silicon wafers are commonly used in electronic devices. In particular, onsurface radical polymerisations have rarely been investigated despite their efficiency in the absence of any catalytic role of the surface, while radical species have been observed as intermediates in cross-coupling reactions on surfaces. Most of the reported results are based on a single tip-induced reaction which causes an intramolecular reorganization or initiation step to result in a single 1D-polymer chain. [1g, 2, 3a] The relative absence of on-surface radical polymerisation is quite surprising, as free radical polymerisation is the main industrial method for obtaining polymeric systems and composite materials. The relatively non-specific nature of free radicals with respect to monomers makes it one of the most versatile polymerisation methods, but at the same time renders their reactions difficult to control. ${ }^{[4]}$ Indeed, 'living' radical polymerisation, where irreversible terminations and transfers are absent while all chains are initiated and grow simultaneously, was considered impossible for many years owing to fast propagation and inevitable radical termination reactions. ${ }^{[5]}$ In the mid-1990s, new methodologies were developed to exploit equilibria between growing radicals and dormant species. ${ }^{[6]}$ These approaches differ in the method of radical generation but all involve the use of a persistent (metallo)radical that reduces the steady-state concentration of the propagating radicals and minimizes the normal termination of living polymers. The simplicity of adding these reagents to a polymerisation reaction has resulted in the ability to synthesize well-defined functionalized (co)polymers. ${ }^{[7,8]}$ However, for a range of applications such as microelectronics, coating technologies and biotechnology, contamination of the final polymer/oligomer by the reagents/additives has become a significant problem and a key limiting factor in their use. Another approach to polymer/oligomer synthesis is that of tandem reactions, which produce macromolecules with new structures and functions. ${ }^{[9]}$ In particular, since radical reactions are ideal for sequencing, for the very fundamental reason that the product of every radical reaction is a radical, tandem radical chemistry may serve as a versatile method in radical oligomerisation. These reactions take place in two or more consecutive steps mediated by the radical's unpaired electron, and have significant advantages over conventional multistep syntheses such as timeand cost-savings, atom economy, waste reduction and energy consumption. ${ }^{[10]}$ However, they are limited by the reactivity of the active sites, which must be well matched so that the product of one chemical transformation does not interfere with the overall tandem sequence.

Here, we propose to use the ability of a STM-tip to generate an organic radical with the free radical polymerization process, with both steps occurring on a semi-conductor surface. We report the first on-surface synthesis of alkyl oligomers on a model silicon surface, mediated by tunnelling electrons from a STM junction. We show, using STM imaging that the on-surface reaction is most likely initiated electronically and involves radical intermediates that preferentially form cross-reacted linear oligomeric products, even on semiconductor surfaces. 


\section{Results and discussion}

\section{Results}

We chose the $\mathrm{Si}(111) \mathrm{V} 3 \times \mathrm{V} 3 \mathrm{R} 30^{\circ}$-B surface as the model semiconductor surface because the subtle balance of molecule-surface and molecule-molecule interactions promotes the formation of extended supramolecular networks ${ }^{[11]}$. As one-electron reduction of aryl alkyl ethers (e.g., cyanoanisole) has already been shown to produce the corresponding phenoxide anion and the alkyl radical[12], we decided to use the same type of compounds in this study. Having previously obtained bilayered networks of aryl alkyl ether derivatives on $\mathrm{Si}(111) \mathrm{V} 3 \times \mathrm{V} 3 \mathrm{R} 30^{\circ}-\mathrm{B}$ surface ${ }^{[13]}$ or ionic alkali halide surfaces ${ }^{[14]}$, we synthesized a pyridyl analog $(1,4-$ di(4',4"-pyridyl)-2,5-bis(decyloxy)benzene, PDB-OC10, Figure 1a) rather than a cyano derivative in order to reinforce molecule surface interactions to observe separate nanolines instead of a compact $2 \mathrm{D}$ supramolecular network on a $\mathrm{Si}(111) \mathrm{V} 3 \times \mathrm{V} 3 \mathrm{R} 30^{\circ}-\mathrm{B}$ surface ${ }^{[15]}$.

PDB-OC10 is based on a phenyl core terminating with two pyridyl moieties, distanced by $1.4 \mathrm{~nm}$ and further core-substituted with two lateral ether alkyl chains (Figure 1a) containing 10 atoms of carbon. The side chain lengths in PDB-OC10 is $3.6 \mathrm{~nm}$. Figures $1 \mathrm{~b}$ and S1 (for a larger scale) show a high resolution STM image, recorded at $110 \mathrm{~K}$, after the deposition of PDB-OC10 by thermal sublimation under ultra-high vacuum conditions on a $\mathrm{Si}(111) \mathrm{V} 3 \times \sqrt{ } 3 \mathrm{R} 30^{\circ}-\mathrm{B}$ substrate maintained at room temperature.
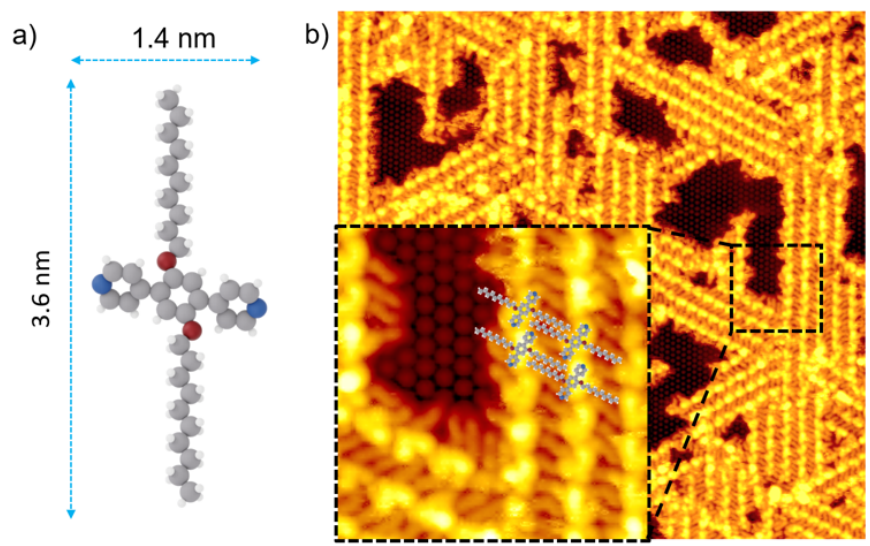

Figure 1. a) Structural model of 1,4-bis(pyridyl)-2,5-bis(decyloxy)benzene PDB-OC10 molecule. Nitrogen atoms: blue, Oxygen atoms: red, Carbon atoms: grey, hydrogen atoms: white. b) Large scale STM image $\left(60 \times 60 \mathrm{~nm}^{2}, \mathrm{~V}_{\mathrm{s}}=-1.3 \mathrm{~V}, \mathrm{I}_{\mathrm{t}}=7 \mathrm{pA}, \mathrm{T}=110 \mathrm{~K}\right)$ representing the self-assembled structure of PDB-OC10 molecules on Si(111) V3xV3R30 $-\mathrm{B}$ substrate. The inset of the image corresponds to black dashed rectangular zoomed area $\left(10 \times 10 \mathrm{~nm}^{2}, \mathrm{~V}_{\mathrm{s}}=-1.3 \mathrm{~V}, \mathrm{I}_{\mathrm{t}}=7 \mathrm{pA}, \mathrm{T}=110 \mathrm{~K}\right)$ of supramolecular network on $\mathrm{Si}(111) \mathrm{V} 3 \times \mathrm{V} 3 \mathrm{R} 30^{\circ}-\mathrm{B}$ surface.

Well-organized stripes consisting of aligned pair of bright protrusions (length: $1.6 \pm 0.1 \mathrm{~nm}$ ) surrounded by slightly darker rods (length: $2.0 \pm 0.2 \mathrm{~nm}$ ), are observed. The stripes follow the three principal directions rotated by $120^{\circ}$ of the substrate, surrounding the empty free space where the silicon adatoms are visible (inset of the Figure $1 \mathrm{~b}$ ). Consistent with the features of PDB-OC10, the bright protrusions can be attributed to the triphenyl cores of PDB-OC10 and the darker paired rods correspond to the interdigitated C10 alkyl chains of two PDB-OC10 molecules involved in two adjacent lines (Figure 1b) [13,16]. Based on our STM observations and measurements, we obtain the adsorption model of the PDB/Si(111)V3xV3R30 -B interface (See insert in Figure 1b). With these results in hand, we were then interested in obtaining a better understanding of the reaction behaviour by scanning a large area of the PDB-OC10/Si(111) V3xV3R30 $-\mathrm{B}$ network at a lower bias voltage. This result is representative of those obtained in repeated experiments for the bias voltage between $-4.5 \mathrm{~V}$ to $0 \mathrm{~V}$. Due to the molecule-molecule and molecule-surface interactions, the alkyl chains of PDB-OC10 molecules are always well visible in the STM images. Notably, at the bias voltage of $-4.5 \mathrm{~V}$, we observed a remarkable modification of the PDB-OC10 molecules in the STM images (See Figure 2). The well-organized network is now disordered and the cross-shape of PDB-OC10 molecules disappeared. If the bias voltage is decreased beyond $-4.5 \mathrm{~V}$, the destruction of the original supramolecular network is still observed.

A further study of the effect of the bias voltage on the PDB-OC10/Si(111)V3xV3R30 $-\mathrm{B}$ interface was then carried out. A 50x50nm ${ }^{2}$ area was imaged by STM at Vs $=-1.3 \mathrm{~V}$, showing the typical STM image features of the PDB-OC10/Si $(111) \mathrm{V} 3 \times \mathrm{V} 3 \mathrm{R} 30^{\circ}-\mathrm{B}$ interface (Figure S2a). Then, the same area was scanned at $-4.5 \mathrm{~V}$. 


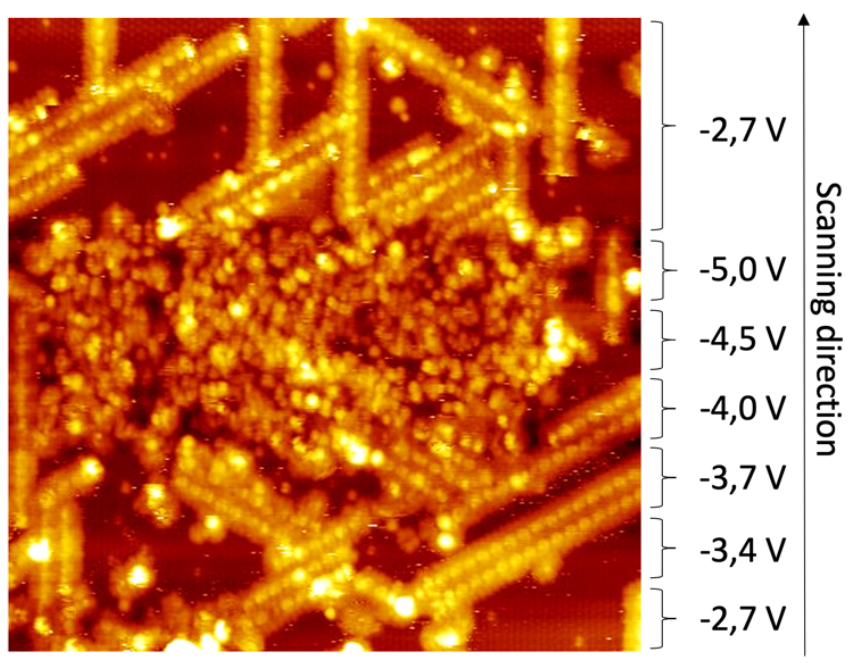

Figure 2. STM image captured while changing bias voltage during the scan shows significant modification of network at $-4.5 \mathrm{~V}\left(60 \times 60 \mathrm{~nm}{ }^{2}, \mathrm{Vs}=\mathrm{variable}\right.$ values shown on image, It $=$ $7 \mathrm{pA}, \mathrm{T}=110 \mathrm{~K})$.

All the cross-shape corresponding to the PDB-OC10 molecules disappeared (Figure $\mathrm{S} 2 \mathrm{~b}$ ), while $\mathrm{Si}(111) \mathrm{V} 3 \times \sqrt{ } 3 \mathrm{R} 30^{\circ}-\mathrm{B}$ surface is unaffected as shown by the uncovered area surrounded by dashed lines in Figure S2b. The same procedure was performed along a line of molecules, leading to the destruction of only the scanned line (Figure S3). Since the cross-shape of PDB-OC10 molecules is not visible, we moved the tip to another area of the PDB-OC10/Si(111)V3xV3R30 $0^{\circ}-\mathrm{B}$ interface, which have been previously scanned only at a voltage below $-4.5 \mathrm{~V}$, showing the ordered supramolecular network (Figure $3 \mathrm{a}$ ) constituted by entire PDB-OC10 molecules.

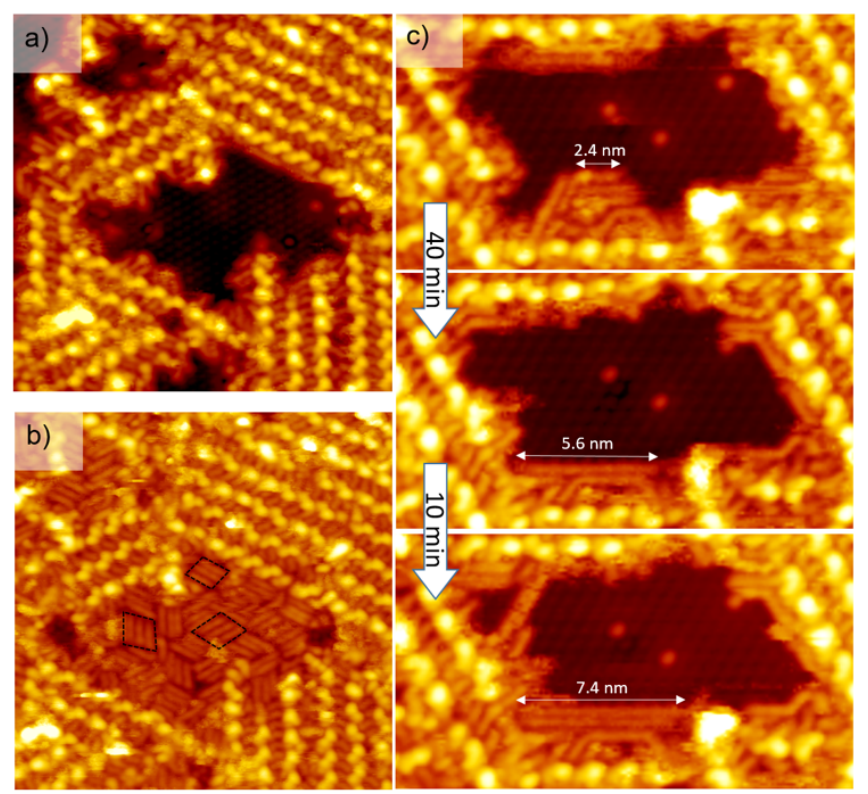

Figure 3. a) STM image $\left(25 \times 25 \mathrm{~nm}^{2}, \mathrm{~V}_{\mathrm{s}}=-1.3 \mathrm{~V}\right.$, It $\left.=7 \mathrm{pA}, \mathrm{T}=110 \mathrm{~K}\right)$ representing an nano-pore inside the supramolecular network. b) The same nano-pore fully filled with rod-like structure released by STM tip during scanning. $c)$ Three STM images $\left(10 \times 20 \mathrm{~nm}^{2}, \mathrm{~V}_{\mathrm{s}}=-1.3 \mathrm{~V}, \mathrm{It}=7 \mathrm{pA}, \mathrm{T}=110 \mathrm{~K}\right)$ showing the growth of rod-like structure in a nanopore.

This intact area is then scanned again at $-1.3 \mathrm{~V}$. During the scan, rod-like features appeared and filled the uncovered zone until it was completely covered by strips of parallel continuous rods (Figure $3 \mathrm{~b}$ ). The rod-like features are arranged parallel in three different domains (see black dashed outlines on Figure $3 \mathrm{~b}$ ) following the three symmetry axes of the $\mathrm{Si}(111) \mathrm{V} 3 \times \mathrm{V} 3 \mathrm{R} 30^{\circ}-\mathrm{B}$ surface. Based on the systematic analysis of more than 20 STM images, a statistical analysis of the size distribution of strips reveals a size repartition centered at a length of $2.1 \mathrm{~nm}$ (Figure S4). In addition, the length of these rod-like structures increases with time (Figure 
3c). Three STM images of the same area have been recorded after 40 and 50 minutes. The length of a rod structure increases from $2.4 \mathrm{~nm}$ to $7.4 \mathrm{~nm}$ while the number of small initial rods decreases. Finally, we have compared the profile of a C10 lateral alkyl chain of an entire PDB-OC10 molecule with the profile of a nanorod on the same STM image (Figure S5). These two profiles have the same shape and differ only by their length. On the basis of all these features, the rods are attributed to alkane oligomers adsorbed on the $\mathrm{Si}(111) \mathrm{V} 3 \times \mathrm{V} 3 \mathrm{R} 30^{\circ}-\mathrm{B}$ surface. The number of carbon atoms in the most common adsorbed alkane was 20 for a rod length of $2.1 \pm 0.2 \mathrm{~nm}$, respectively. In addition, the rod corresponding to the decane (10 carbon atoms) and longer alkanes (like hexacontane, 60 carbon atoms $7.4 \mathrm{~nm}$, Figure 3c) were very rarely observed. The observation, of the growth of long alkanes definitively indicates that a polymerization process occurs on the surface.

\section{Discussion}

The formation of oligomeric alkanes from aromatic species containing only ether side chains as precursors has not yet been reported in the literature. The resulting mechanism should involve at least two steps: (i) activation of the C-O bonds of the aromatic precursors at a fixed bias voltage and then (ii) on-surface oligomerisation of the generated species. For instance, the activation mechanism of $\mathrm{C}-\mathrm{O}$ bonds in alkyl aryl ether derivatives has been extensively investigated in solution ${ }^{[12]}$ and most recently described by Yang et al. on noble metal surfaces [17]. In the latter case, the authors suggested that the dealkylation process is based on a thermally-induced intramolecular prototropy from a hydrogen atom of the alkyl chain to the oxygen atom of the ether function. In solution, the dealkylation of aryl alkyl ethers can originate from a reduction (through an electron transfer ${ }^{12}$ ), or can be catalysed by a Lewis or Brønsted acid [18] or by organometallic complexes (oxidative addition [19]). In our experiments, it is reasonable to rule out that the mechanism is based on a catalyst because no external catalytic species were introduced on the surface. Since the dealkylation reaction takes place even at low temperatures, a thermally-assisted mechanism is also unsuitable. As the transformation occurs at negative bias voltage, this involves electrons that tunnel from the substrate, through the adsorbed layer to the STM tip. Then, an electron originates from the valence band of the substate can be captured by low-lying energy empty states of PDB-OC10 molecule ${ }^{[20]}$ to generate an anion that relax through a dissociative electron attachment (DEA) mechanism ${ }^{[19}$, 21]. The relaxation of that anion on the $\mathrm{Si}(111) \mathrm{V} 3 \times \mathrm{V} 3 \mathrm{R} 30^{\circ}-\mathrm{B}$ surface leads to the dissociation of PDB-OC10 into a phenoxide moiety and an alkyl radical. A similar reaction path was already demonstrated in the electrochemical reduction of cyanoanisole in solution [12]. From DFT calculations, the electronic structure of PDB-OC10/Si(111)-B system shown in Figure 4 supports such DEA mechanism for which the energy of empty states (mostly C-aromatic) above Fermi level (see Fig.4(d)) are in the same energy range than the bias voltage used in STM experiments where the reaction occurs. Moreover, additional DFT calculations on gas phase species (see Figure S6) indicate that C-O bond breaking is easier on the aliphatic side than the aromatic side by around $1.8 \mathrm{eV} / \mathrm{bond}$.

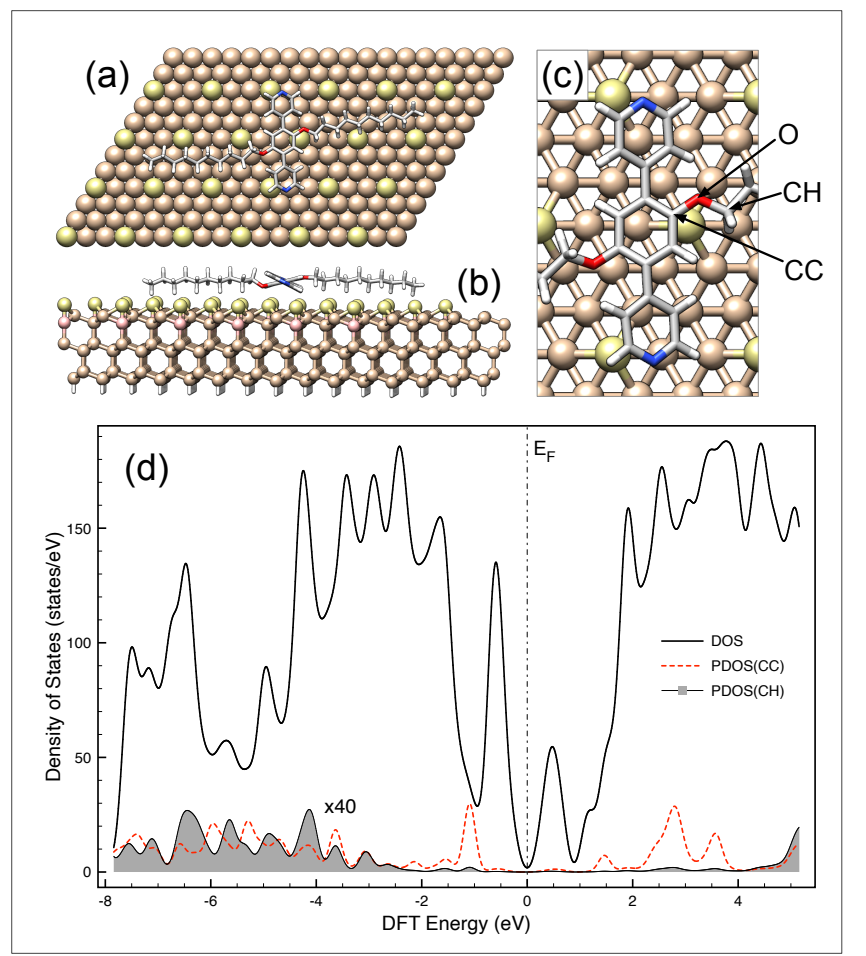

Figure 4. (a) top view, (b) side view and (c) zoom view of the optimized supercell used to determine the electronic structure of PDB-OC10 adsorbed on $\mathrm{Si}(111)) \mathrm{V} 3 \mathrm{xV} 3 \mathrm{R} 30^{\circ}-\mathrm{B}$ surface by DFT. Clearly in (a), the C10 chains of PDB-OC10 (92 atoms) are well-aligned along Si-adatom rows that we have identified within the substrate ( 582 atoms) through brighter color for clarity. The density of states (DOS) and the projection (PDOS) profiles of the system are reported in (d) where the PDOS of aromatic (CC) and aliphatic carbon atom (CH) are the summed contribution of each species around $O$ moieties, all projections are multiplied by 40 . 
The cleavage efficiency is $100 \%$, leading to complete disorganization of the initial supramolecular network. It is worth noting that after $\mathrm{C}-\mathrm{O}$ bond activation, the resulting phenoxide moieties were rarely observed on the STM images. This may be explained by their low adsorption energies on the $\mathrm{Si}(111) \mathrm{V} 3 \times \mathrm{V} 3 \mathrm{R} 30^{\circ}-\mathrm{B}$, leading to their desorption (Figure S7). A comparison of adsorption energy for both species on $\mathrm{Si}(111)$-B obtained by DFT calculations also supports a weaker interaction of phenoxide than PDB-OC10 on the surface (see SI, Figure S8). The alkane derivatives only reappear as a periodic supramolecular network by scanning the uncovered areas of the Si(111) $\sqrt{ } 3 \times \sqrt{ } 3 R_{3} 0^{\circ}-\mathrm{B}$ surface (Figures 3 and S9). In addition, tip instabilities are observed during the scanning, indicated that molecules are adsorbed on the STM tip (Figure S10). These features indicate that (i) the STM tip can act as a reservoir of $\mathrm{C} 10$ alkyl radicals, which can be released on the surface and (ii) These C10 radicals are free to diffuse on the $\mathrm{Si}(111) \sqrt{ } 3 \times \sqrt{ } 3 \mathrm{R} 30^{\circ}-\mathrm{B}$ surface.

From a mechanistic point of view, the combination of electron-attachment (reduction) and C-O bond cleavage can be considered as the initiation step of a radical oligomerisation (Figure 5).

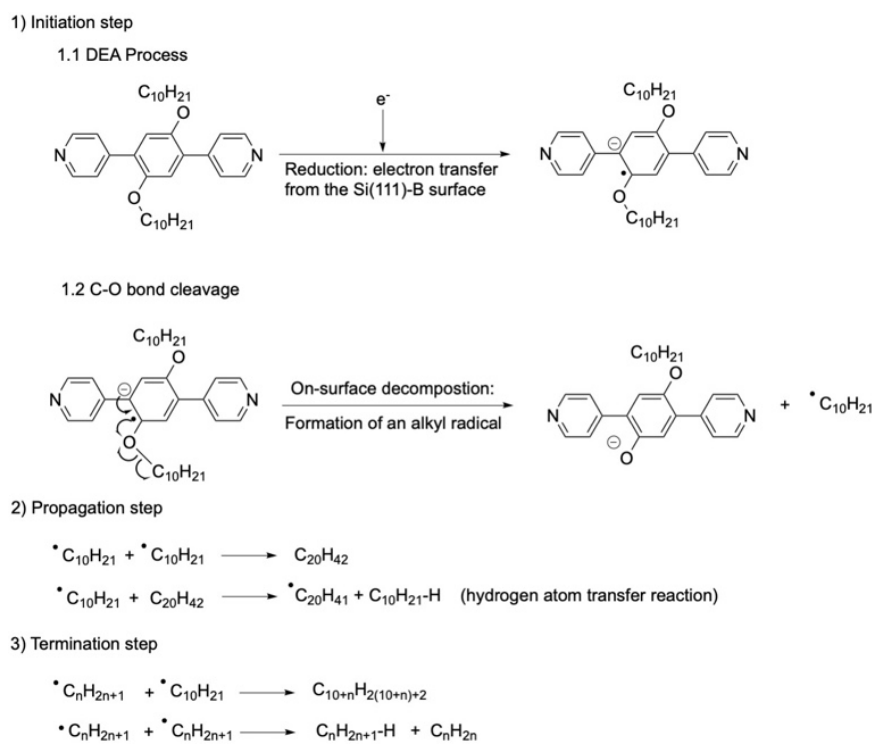

Figure 5. C-O bond activation and cleavage followed by oligomerisation of the ensuing alkyl radicals on a Si(111) V $3 \times \mathrm{V} 3 \mathrm{R} 30^{\circ}-\mathrm{B}$ surface. 1) DEA process by electron attachment leading to the formation of a radical-anion at Vs <-4.5 V. C-O bond cleavage leading to the formation of a phenoxide anion and an alkyl radical. The combination of these two steps is the initiation step of the radical oligomerisation of alkyl chains. 2) Propagation of the radical oligomerisation. A chain-transfer reaction of radical leads to the growth of the length of produced alkanes. 3) Termination of the radical oligomerisation by two main mechanisms: combination between two radicals or disproportionation.

Since the procedure of DEA manipulation leads to the collective formation of radicals by scanning large areas of the starting supramolecular network of PBD-OC10 molecules, the resulting radicals can react with each other by radical oligomerisation. The chain growth step is regulated by the rate of radical formation, as is the propagation step of a radical oligomerisation (Figure 5). In contrast to oligomerisation in solution, alkyl radicals have to diffuse to react, limiting the possibilities of the substrates to react and explaining why only linear alkanes are observed. When alkanes are long, chain growth can be stopped by two main termination processes (Figure 5). Since residual hydrogen gas is present in very low amount in the UHV chamber, an additional termination step that would involve a reaction of radicals with $\mathrm{H}_{2}$ was safely ruled out. The occurrence of this type of side reactions could explain the fairly modest lengths observed for the final alkanes. However, in agreement with previous observations, we considered that the 2D confined geometry could also favour certain reactions that are not usually observed. Due to the unique space confinement, the formation of linear oligomers of similar molecular weights can be controlled. This finding is consistent with the statistical analysis of the size distribution of alkanes adsorbed on Si(111)V3xV3R30 $0^{\circ}$-B surface and the step-by-step growth described in Figure 3c, which correspond to monitoring of the propagation step by STM images.

\section{Conclusions}

In summary, we have used STM under UHV conditions and with some voltage application to initiate the synthesis of alkyl oligomers on a semiconductor surface. We have shown that the lack of reactivity of semiconductors with respect to a metal surface can be circumvented by using the STM-tip as an active role-player. Indeed, all these experiments clearly demonstrate that the observed transformations are triggered by a local dissociative electron (tunnelling) attachment and do not require any another "catalytic" role of surfaces. This allows the collective formation of electron-induced radicals that are able to cross-react in a controlled manner without adding any additives to produce alkyl oligomers. The origin of the experimentally observed selectivity towards oligomer 
products has been attributed to the 1D restriction of the reactive species along the surface. This tunnelling electron-induced radical oligomerization is a major step towards the fabrication of molecular electronic devices and novel nanomaterials.

\section{Conflicts of interest}

There are no conflicts to declare.

\section{Acknowledgements}

We thank Dr B. Grandidier (IEMN, Lille, France) and Dr M.-L. Bocquet (ENS, Paris, France) for fruitful discussions. The authors acknowledge the financial support from the French National Research Agency through contract OVATION (ANR-19-CE09-0020) and from the Pays de Montbéliard Agglomération. C.M.T. is grateful to the Institut Universitaire de France (IUF). A.R. acknowledges the support from the Natural Sciences and Engineering Research Council of Canada (NSERC), and he is grateful to Calcul Québec and Compute Canada for providing computational resources.

\section{References}

1 a) L. Grill, M. Dyer, L. Lafferentz, M. V. Persson, S. Hecht, Nat. Nanotech., 2007, 2, 687; b) L. Cai, P. Ruffieux, R. Jaafar, M. Bieri, T. Braun, M., Blankenburg, A. P. Seitsonen, M. Saleh, X. Feng, K. Mullen, R. Fasel, Nature, 2010, 466, 470; c) M. Matena, T. Riehm, M. Stöhr, T. A. Jung, L. H. Gade, Angew. Chem., Int. Ed., 2008, 47, 2414; d) P. A. Held, H. Fuchs, A. Studer, Chem. Eur. J., 2017, 23, 5874; e) H. Sakaguchi, S. Song, T. Kojima, T. Nakae, Nat. Chem., 2017, 9, 57; f) N. Pvalicek, Z. Majzik, S. Collazos, G. Meyer, D. Perez, E. Guitian, D. Pena, L. Gross, ACS Nano, 2017, 11, 10768; g) S. Kawai, H. Sang, L. Kantorovitch, K. Takahashi, K. Nozaki, S. Ito, Angew. Chem., Int. Ed., 2020, 59,10842; h) B. Yang, B. Dong, L. Chi, ACS Nano, 2020, 14, 6376; i) S. Clair, D. G. de Oteyza, Chem. Rev., 2019, 119, 4717; j) M. Lackinger, Chem. Commun., 2017, 53, 7872; k) M. Di Giovannantonio, G. Contini, J. Phys. Condens. Matter, 2018, 30, 093001; I) A. Gourdon, Onsurface Synthesis, Springer, Switzerland, 2016.

2 a) S.-W. Hla, L. Bartels, G. Meyer, K.-H. Rieder, Phys. Rev. Lett. 2000, 85, 2777; b) A. Riss, S. Wickenburg, P. Gorman, L. Z. Tan, H.-Z. Tsai, D. G. de Oteyza, Y.-C. Chen, A. J. Bradley, M. M. Ugeda, G. Etkin, S. G. Louie, F. R. Fischer, M. F. Crommie, Nanolett., 2014, 14, 2251; c) Y. Okawa, M. Aono, Nature, 2001, 409, 683; e) V. Verstraete, B. E. Hirsche, J. Greenwood, S. De Feyter, Chem. Commun., 2017, 53, 4207; d) S.Zint, D. Ebeling, T. Sclöder, S. Ahles, D. Mollenhauer, H. A. Wegner, A. Schirmeisen, ACS Nano, 2017, 11, 4183; e) A. SanchezGrande, J. I. Urgel, A. Cahlik, J. Santos, S. Edalatmanesh, E. Rodriguez-Sanchez, K. Lauwaet, P. Mutombno, D. Nachtigallova, R. Nieman, H. Lischka, B. de la Torre, R. Miranda, O. Gröning, N. Martin, P. Jelinek, D. Ejica, Angew. Chem., Int. Ed., 2020, 59, 17594; f) G. Galeotti, M. Fritton, M. Lackinger, Angew. Chem., Int. Ed., 2020, 10.1002/anie.202010833.

3 a) F. Para, F. Bocquet, L. Nony, C. Loppacher, M. Féron, F. Chérioux, D. Z. Gao, F. F. Canova, M. B. Watkins, Nat. Chem., 2018, 10, 1112; b) R. Linder, P. Rahe, M. Kittelmann, A. Gourdon, R. Bechstein, A. Kuhnle, Angew. Chem., Int. Ed., 2014, 53, 7952; c) C.-A. Palma, K. Diller, R. Berger, A. Welle, J. Bjork, J. I. Cabellos, D. J. Mowbray, A. C. Papageorgiou, N. P. Ivleva, S. Matich, E. Margapoti, R. Nlessner, B. Menges, J. Reichert, X. Feng, H. J. Rader, F. Klappenberger, K. Mullen, J. V. Barth, J. Am. Chem. Soc., 2014, 136, 4651.

4 For instance, almost $40 \%$ of all polymers produced in the United States are produced by this mechanism.

$5 \quad$ K. Matyjaszewski, N. V. Tsarevsky, Nat. Chem., 2009, 1, 276 and references therein.

6 These methods include atom-transfer radical polymerization (ATRP) and stable free-radical polymerization (SFRP), which proceed with reversible termination, and reversible addition-fragmentation transfer (RAFT), which proceeds with reversible chain transfer. See for instance: a) G. Moad, D. H. Solomon The Chemistry of Radical Polymerization, 2nd ed., Elsevier Science, Oxford, UK, 2006; b) Handbook of Radical Polymerization (Eds.: K. Matyjaszewski, T. P. Davis), Wiley Interscience: New York, 2002; c) W. A. Braunecker, K. Matyjaszewski, Prog. Polym. Sci., 2007, 32, 93.

7 V. Sciannamea, R. Jérôme, C. Detrembleur, Chem. Rev., 2008, 108, 1104.

8 a) M. Szwarc, M. Levy, R. Milkovich, J. Am. Chem. Soc., 1956, 78, 2656; b) M. Szwarc, Nature, 1956, 178, 1168. c) O. W. Webster, Science, 1991, 251, 887; d) S. K. Varshney, R. Jérôme, P. Bayard, C. Jacobs, R. Fayt, P. Teyssié, Macromolecules, 1991, $24,4997$.

9 C. Robert, F. de Montigny, C. M. Thomas, Nature Comm. 2011, 2, 586 and references therein.

10 C. Robert, C. M. Thomas, Chem. Soc. Rev., 2013, 42, 9392 and references therein.

11 a) B. Baris, V. Luzet, E. Duverger, Ph. Sonnet, F. Palmino, F. Chérioux, Angew. Chem., Int. Ed., 2011, 50, 4094; b) S. R. Wagner, R. R. Lunt, P. Zhang, Phys. Rev. Lett. 2013, 110, 086107; c) G. Copie, F. Cléri, Y. Makoudi, C. Krzeminski, M. Berthe, F. Cherioux, F. Palmino, B. Grandidier, Phys. Rev. Lett. 2015, 114, 066101; d) Y. Makoudi, J. Jeannoutot, F. Palmino, F. Cherioux, G. Copie, C. Krzeminski, F. Cléri, B. Grandidier, Surf. Sci. Rep., 2017, 72, 316.

12 a) M. D. Koppang, N. F. Woosley, D. E. Bartak, J. Am. Chem. Soc., 1984, 106, 2799; b) L. Testaferri, M. Tiecco, M. Tingoli, D. Chianelli, M. Montanuc, Tetrahedron, 1982, 38, 3687.

13 Y. Makoudi, M. Beyer, S. Lamare, J. Jeannoutot, F. Palmino, F. Chérioux, Nanoscale, 2016, 8, 12347.

14 a) A. Amrous, F. Bocquet, L. Nony, F. Para, C. Loppacher, S. Lamare, F. Palmino, F. Chérioux, D. Z. Gao, F. F. Canova, M. B. Watkins, A. L. Shluger, Adv. Mater. Interfaces, 2014, 1, 1400414.

15 G. Zhan, M.-A ; Dubois, Y. Makoudi, S. Lamare, J. Jeannoutot, X. Bouju, A. Rochefort, F. Palmino, F. Chérioux, J. Phys. Chem. C, 2017, $121,8427$.

16 T. Kudernac, S. Lei, J. A. A. W. Elemans, S. De Feyter, Chem. Soc. Rev., 2009, 38, 402.

17 B. Yang, H. Lin, K. Miao, P. Zhu, L. Liang, K. Sun, H. Zhang, J. Fan, V. Meunier, Y. Li, Q. Li, L. Chi, Angew. Chem. Int. Ed., 2016, 55, 9881.

18 M. Tobisu, N. Chatani, Acc. Chem. Res., 2015, 48, 1717.

19 S. A. Weissman, D. Zwege, Tetrahedron, 2005, 61, 7833. 
20 a) W. Chen, D. Qi, X. Gao, A. T. S. Wee, Prog. Surf. Sci., 2009, 84, 270; b) S. R. Wagner, B. Huang, C. Park, J. Feng, M. Yoon, P. Zhang, Phys. Rev. Lett., 2015, 115, 096101; c) S. Lindner, M. Franz, M. Kubicki, S. Appelfeller, M. Dähne, H. Eisele, Phys. Rev. B, 2019, 100, 245301; d) R. G. A. Veiga, R. H. Miwa, A. B. McLean, Phys. Rev. B, 2016, 93, 115301; e) N. P. Guisinger, M. E. Greene, R. Basu, A. S. Baluch, M. C. Hersam, Nanolett., 2004, 4, 55; f) M. Kubicki, S. Lindner, M. Franz, H. Eisele, M. Dähne, J. Vac. Sci. Technol. B., 2020, 38, 042803.

21 a) M. Stepanovic, Y. Parlay, M. Allan, J. Chem. Phys., 1999, 110, 11376; b) C. Bulliard, M. Allan, S. Grimme, Int. J. Mass Spectr., 2001, 205, 43; c) R. Martel, Ph. Avouris, I.-W. Lyo, Science, 1996, 272, 385. 